\title{
Research on Stress and Strain of 304 Stainless Steel in Turning Process Based on Oxley - Welsh Theory
}

\author{
Gang Zhan ${ }^{1,3}$, Lin $\mathrm{He}^{2,1^{*}}$,Hong-wan Jiang ${ }^{1}$ and Zhong-fei Zou ${ }^{1}$ \\ ${ }^{1}$ College of Mechanical Engineering, Guizhou University, Guiyang,550025, China \\ ${ }^{2}$ Guizhou Normal College, Guiyang,550018,China \\ ${ }^{3}$ Guizhou Vocational Technology of Electronics \& Information,Kaili,556000,China
}

\begin{abstract}
Keywords: Oxley-Welsh Theory, Work Hardening Effect, Shear Tlow Stress, Hydrostatic Stress, Experimental Research.
\end{abstract}

\begin{abstract}
Considering the size effect, temperature effect and hardening effect of the material in the shear zone, the shear strain and the shear strain rate of the material in the shear zone are studied by theoretical calculation and experimental study. Hydrostatic stress and shearing flow stress with the cutting amount of change. The results show that the stress difference between hydrostatic stress and shearing flow stress is largest when the cutting amount is $V_{c}=60 \mathrm{~m} / \mathrm{min}, \mathrm{f}=0.15 \mathrm{~mm} / \mathrm{r}$, and $\mathrm{a}_{p}=$ $1 \mathrm{~mm}$, and the material even plasticity Deformation of the best, the workpiece has good service performance, in the course of work to withstand the impact load capacity is relatively strong.
\end{abstract}

\section{Introduction}

As for the hardening of metal materials, related research institutions and scholars at home and abroad have conducted some studies. Professor Yang Ruicheng, Lanzhou University of Technology, [1] has studied 304,410S, 430 and 409L four kinds of stainless steel material hardening behavior, which shows that 304 stainless steel hardening capacity is much higher than the other three kinds of stainless steel. Zhou Xiaofen of Shanghai University[2] has studied the tensile strain hardening behavior of TWIP steel, showing that the strain hardening during the tensile process is dislocation strengthening stage and twin strengthening stage. Wang Zhifu of Xinjiang Petroleum Exploration Research Institute mainly has studied the effect of strain rate on strain hardening at room temperature, from the two aspects of strain rate sensitivity index and strain hardening index[3-4], which shows that the strain rate has a certain sensitivity on the strain hardening behavior of 304 stainless steel. Qingdao University of Technology, Yang Yong [5] has proposed the constitutive model of material construction method based on orthogonal cutting theory. By the cutting test, the result shows that aerospace aluminum alloy in the cutting process has obvious strain hardening characteristics. Terherst M [6] of Aachen Machine Tool Laboratory in Germany has studied strain hardening hindering the movement of dislocation in the forming process of cold metal, to improve the fatigue strength and load-carrying capacity of the workpieces. Then, establishing the model of the strain hardening of the workpieces by DEFORM finite element software investigates the effects of temperature and strain rate on the flow stress, which is verified by the microhardness test. Bambach M. [7] of the Brandenburg University of Technology in Germany has developed a strain hardening model for two test materials by the isothermal hot compression test of titanium aluminide and comparing the work hardening behavior of $25 \mathrm{MoCrS} 4$ surface hardened steel. And the flow stress is accurately predicted over a wider range of deformation conditions. The above results from different angles carry out the study of stress and strain and work hardening.Based on the Oxley-Welsh theory, considering the size effect of the shear zone, the material hardening effect and the temperature effect, combined with the cutting experimental data, the effects of the cutting amount on the stress-strain of the material shear zone, hydrostatic stress and shear flow Stress with the cutting amount of change. 


\section{Cutting Experiments}

Cutting experiments using carbide new micro-pit tool, tool working angle shown in Table 1, test machine for the C6136HK CNC lathe, dynamometer for the Kistler-9257B, the workpiece diameter of $60 \mathrm{~mm} 304$ stainless steel bar, the workpiece material physical and mechanical properties shown in Table 2, cutting force test platform shown in Figure 1.

Table 1. Geometric angles of the tool

\begin{tabular}{ccccccc}
\hline $\begin{array}{c}\text { Geometric } \\
\text { angle }\end{array}$ & $\begin{array}{c}\text { Tool } \\
\text { angle } \varepsilon_{\mathrm{r}}\end{array}$ & $\begin{array}{c}\text { Rake } \\
\text { angle } \gamma_{0}\end{array}$ & $\begin{array}{c}\text { Clearance } \\
\text { angle } \alpha_{0}\end{array}$ & $\begin{array}{c}\text { Inclination } \\
\text { angle } \lambda_{s}\end{array}$ & $\begin{array}{c}\text { Main cutting } \\
\text { edge angleK }\end{array}$ & $\begin{array}{c}\text { Approach } \\
\text { Angle } \psi_{r}\end{array}$ \\
\hline Value $\left(^{\circ}\right)$ & 80 & 8 & 7 & -5 & 95 & -5 \\
\hline
\end{tabular}

Table 2. Property parameters of material

\begin{tabular}{cccccc}
\hline Material & $\begin{array}{c}\text { Density } \\
(\mathrm{g} / \mathrm{cm} 3)\end{array}$ & $\begin{array}{c}\text { Tensile } \\
\text { strength(MPa) }\end{array}$ & Hardness & Poisson's ratio & $\begin{array}{c}\text { Elastic modulus } \\
(\mathrm{GPa})\end{array}$ \\
\hline Tool & 13.8 & 520 & $91.8 \mathrm{HRA}$ & 0.23 & $540-600$ \\
Workpiece & 7.93 & 1080 & 30HRC & 0.247 & 206 \\
\hline
\end{tabular}

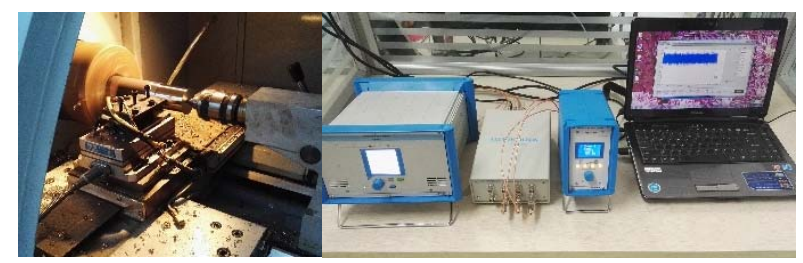

Figure 1.Cutting test platform

Cutting experimental program and experimental data as shown in Table 3 .

Table 3. Cutting test scheme and test data

\begin{tabular}{ccccc}
\hline NO. & $\mathrm{v}_{\mathrm{c}}(\mathrm{m} / \mathrm{min})$ & $f(\mathrm{~mm} / \mathrm{r})$ & $\mathrm{a}_{\mathrm{p}}(\mathrm{mm})$ & $\mathrm{a}_{\mathrm{c}}(\mathrm{mm})$ \\
\hline 1 & 180 & 0.15 & 1 & 0.2933 \\
2 & 150 & 0.15 & 1 & 0.2960 \\
3 & 120 & 0.15 & 1 & 0.3077 \\
4 & 90 & 0.15 & 1 & 0.3130 \\
5 & 60 & 0.15 & 1 & 0.3210 \\
6 & 150 & 0.3 & 1 & 0.3967 \\
7 & 150 & 0.25 & 1 & 0.3293 \\
8 & 150 & 0.2 & 1 & 0.3160 \\
9 & 150 & 0.15 & 1 & 0.2960 \\
10 & 150 & 0.1 & 1 & 0.2027 \\
11 & 150 & 0.15 & 2.5 & 0.3150 \\
12 & 150 & 0.15 & 2 & 0.2997 \\
13 & 150 & 0.15 & 1.5 & 0.2909 \\
14 & 150 & 0.15 & 1 & 0.2960 \\
15 & 150 & 0.15 & 0.5 & 0.2635 \\
\hline
\end{tabular}

\section{Oxley-Welsh Theory}

In the past, all kinds of shear angle theory formulas did not consider the work hardening of the material being machined. Merchant assumed that the shear stress was independent of the shear strain. Lee-Shaffer and Shaw assumed that the material to be machined was the ideal rigid-plastic material. The effects of work hardening and strain rate effects were considered by Oxley. 

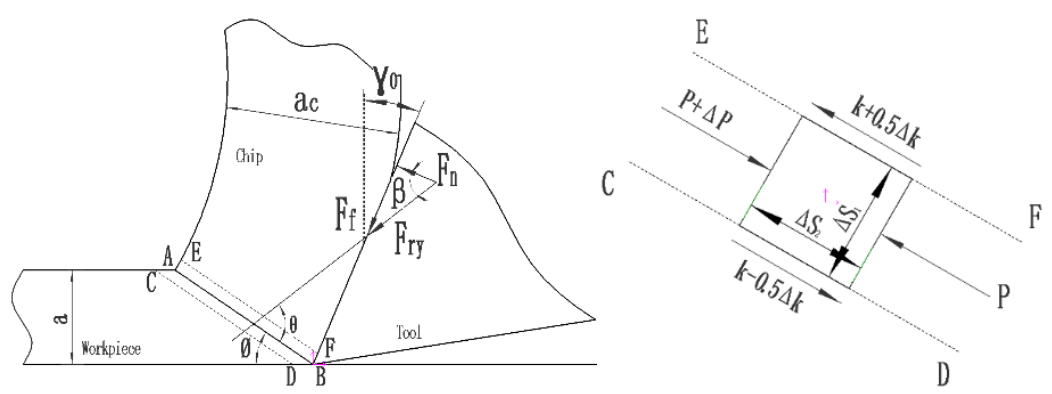

(a) Shear zone(b) Shear zone element

Figure 2.The model of shear zone

According to Figure 2 (a), $\phi$ is the Shear Angle; $\gamma_{0}$ is the Rake Angle; $\beta$ is the Friction Angle; $\psi_{r}$ is the Tool Clearance Angle; $a$ is the Cutting Thickness; the angle between Cutting force $\left(F_{r}\right)$ and $\mathrm{AB}$ is $\theta$; $\mathrm{v}_{c}$ is the Cutting Speed; $\mathrm{f}$ is the federate; $\mathrm{AB}, \mathrm{CD}$, and EF represent shear planes; $\Delta_{s 1}$ is the width of the shear zone; $\Delta_{s 2}$ is The length of the shear zone element AB:

$$
\mathrm{a}=\mathrm{f} \cdot \cos \varphi_{r}
$$

$$
\emptyset=\theta-\beta+\gamma_{0}
$$

$$
\begin{gathered}
\gamma=\frac{\cos \gamma_{0}}{\sin \emptyset \cdot \cos \left(\varnothing-\gamma_{0}\right)} . \\
\gamma=\frac{\cos \gamma_{0}}{\cos \left(\varnothing-\gamma_{0}\right)} \cdot \frac{\mathrm{v}_{\mathrm{c}}}{\Delta \mathrm{s}_{1}} .
\end{gathered}
$$

The material passing through the band-like shear region as shown in Figure. 2 (b), AB shear stress is the shear flow stress $\mathrm{k}$; the normal stress is hydrostatic stress $\mathrm{p}$. Let the total flow stress along the $\mathrm{AB}$ normal shear flow be $\Delta \mathrm{k}$; The total stress change along the $\mathrm{AB}$ is $\Delta \mathrm{p} ; \square \mathrm{A}$ and $\square \mathrm{Bare}$ the hydrostatic compressive stresses at point $A$ and point $B$ respectively. Considering the balance of the elements in the shear zone, then:

$$
\begin{aligned}
\Delta \mathrm{p}=\frac{\Delta \mathrm{k}}{\Delta \mathrm{s}_{1}} \cdot \Delta \mathrm{s}_{2} . \\
\quad \mathrm{p}_{\mathrm{A}}-\mathrm{p}_{\mathrm{B}}=\frac{\Delta \mathrm{k}}{\Delta \mathrm{s}_{1}} \cdot \frac{\mathrm{a}}{\sin \varnothing} .
\end{aligned}
$$

Considering the equilibrium condition, then:

$$
\mathrm{p}_{\mathrm{A}}=\mathrm{k}\left[1+2\left(\frac{\pi}{4}-\emptyset\right)\right]
$$

Figure 3 (b) for the ideal cutting plasticity curve, the figure available:

$$
\Delta \mathrm{k}=\mathrm{m} \cdot \gamma
$$

In the formula, $\mathrm{m}$ is the slope (the work hardening rate) of the plastic stress-strain curve at the average shear strain rate in the shear zone; and $\gamma$ is the shear strain along EF.

$$
\frac{\mathrm{a}}{\Delta \mathrm{s}_{1} \cdot \sin \emptyset}=10
$$

$\square 0$ is the initial shear flow stress; $p$ a is the average shear flow stress in the shear zone; $\mathrm{m}$ and $\square 0$ can be calculated according to the results of Kececioglu's study [8], and finally the shear flow stress $\mathrm{k}$ in the shear zone and the average shear flow stress pa can be calculated. According to the 
formulas (2), (3), (8), (9), (10) and (12), the Oxley-Welsh cutting model is given by Eq. (13).

$$
\begin{gathered}
\mathrm{k}=\mathrm{k}_{0}+\frac{\Delta \mathrm{k}}{2} . \\
\mathrm{p}_{\mathrm{a}}=\frac{\mathrm{p}_{\mathrm{A}}+\mathrm{p}_{\mathrm{B}}}{2} . \\
\tan \theta=\frac{\mathrm{p}_{\mathrm{a}}}{\mathrm{k}} . \\
\varnothing=\tan ^{-1}\left[1+2\left(\frac{\pi}{4}-\varnothing\right)-\frac{10 \mathrm{~m} \cos \gamma_{0}}{2 \mathrm{k}_{0} \sin \emptyset \cos \left(\varnothing-\gamma_{0}\right)+\mathrm{m} \cos \gamma_{0}}\right]-\beta+\gamma_{0} .
\end{gathered}
$$

\section{Analysis of Experiments and Simulation Results}

According to the above-mentioned Oxley-Welsh cutting model and cutting experimental data, the variational trend that shear strain and shear strain rate of the shear zone vary with the cutting amount in the cutting of the 304 stainless steel are obtained by the formulas (1) to (13), as the Figure 3 shows.
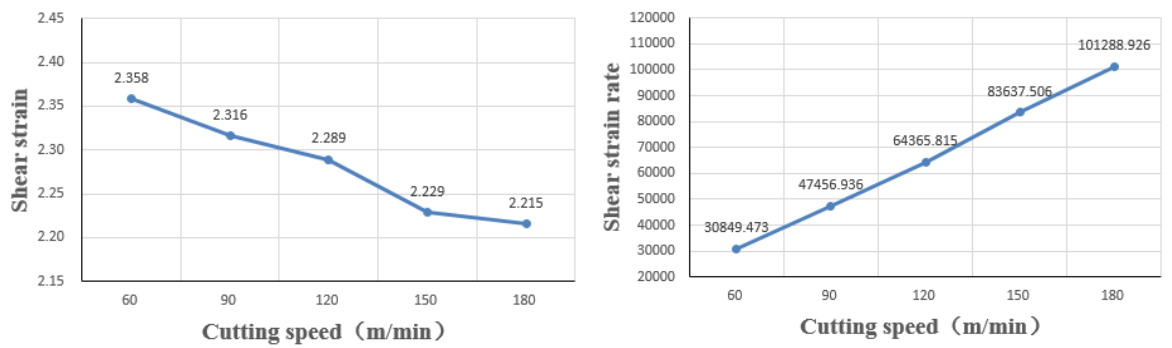

(a) Influence of cutting speed on shear strain(b)Influence of cutting speed on shear strain rate
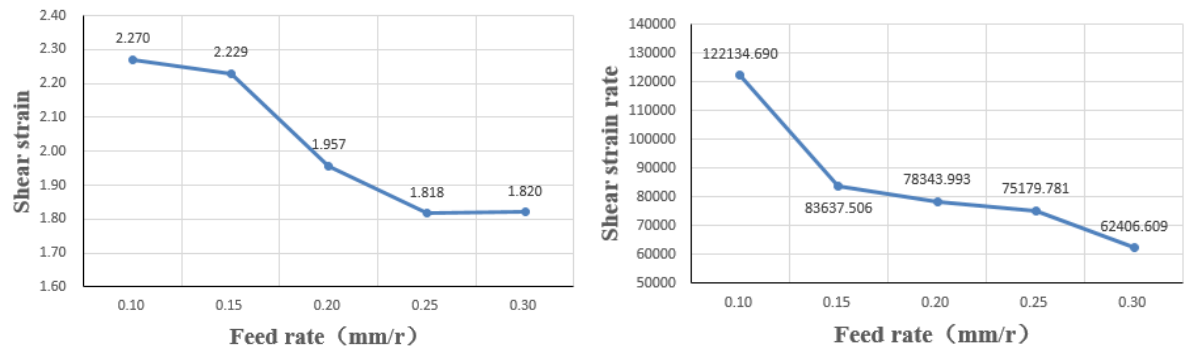

(c)Influence of feed rate on shear strain(d)Influence of feed rate on shear strain rate
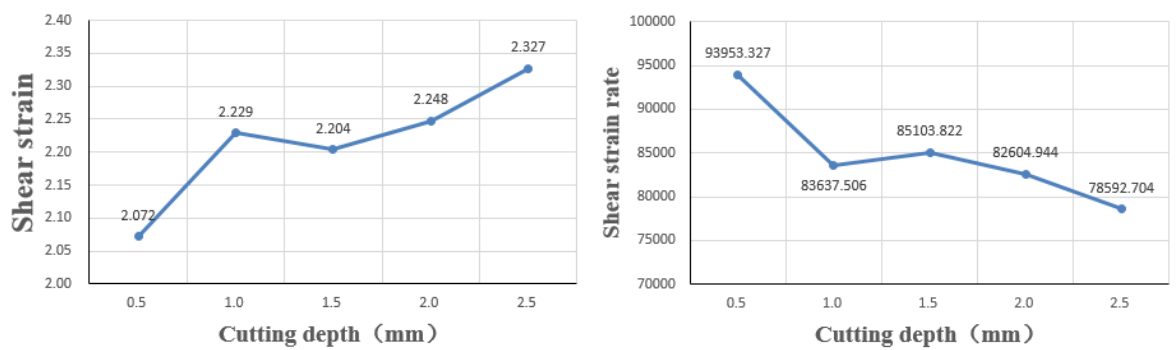

(e)Influence of cutting depth on shear strain(f)Influence of cutting depth on shear strain rate

Figure 3.The change trend of shearstrain and shear strain rate with cutting parameters

According to Figure3 (a) and Figure3 (b), the shear strain of the shear zone decreases gradually with the increase of the cutting speed, while the shear strain rate increases gradually with the increase of the cutting speed. From Figure3 (c) and Figure3 (d), with the increase of feed rate, the shear strain of the shear zone decreases slowly at the initial stage; decreases sharply at the middle 
stage; slightly increases at the final stage, whereas the shear strain rate decreases sharply at the initial stage; slightly decreases at the middle stage; sharply decreases again at the final stage. As shown in Figure 3 (e) and Figure 3(f), with increasing cutting depth, the strain of the shear zone shows a fluctuating upward trend, while the shear strain rate shows a downward trend.

Based on the results shown in Figure 3 and then through the formulas (5) to (13) a series of numerical calculation, you can draw the relationship of the cutting amount on the shear flow stress and hydrostatic stress, as shown in Figure.4.
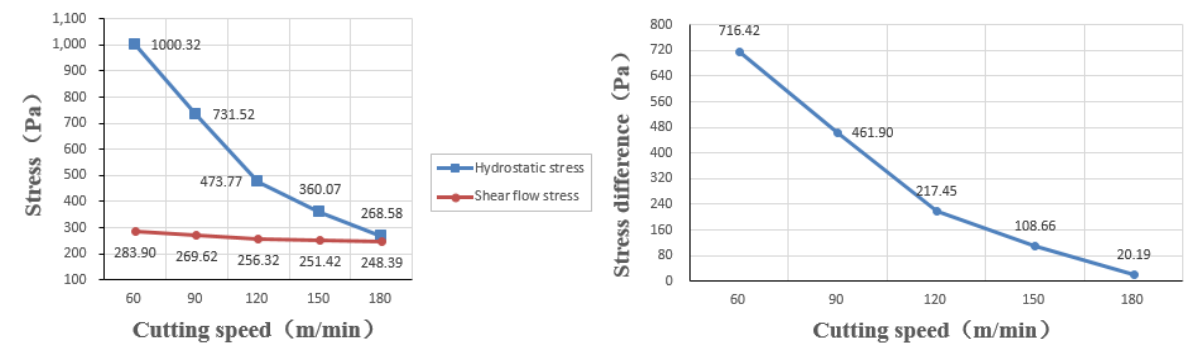

(a) Influence of cutting speed on stress(b)Influence of cutting speed on stress difference
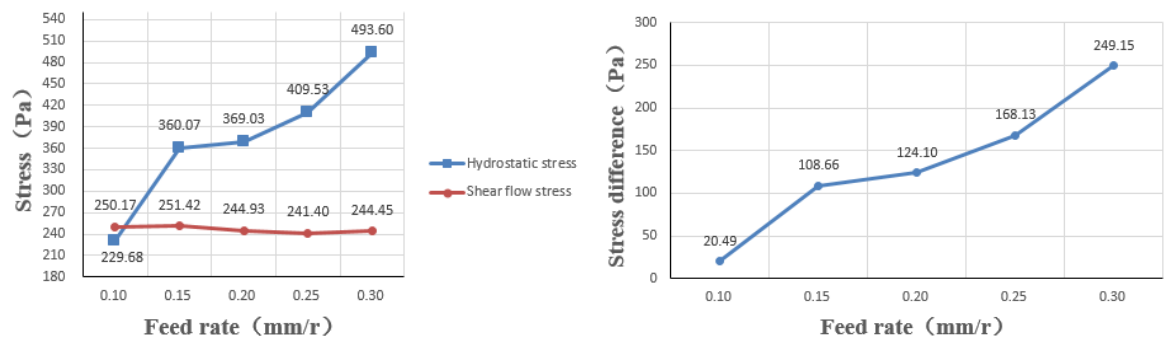

(c)Influence of feed rate on stress(d)Influence of feed rate on stress difference
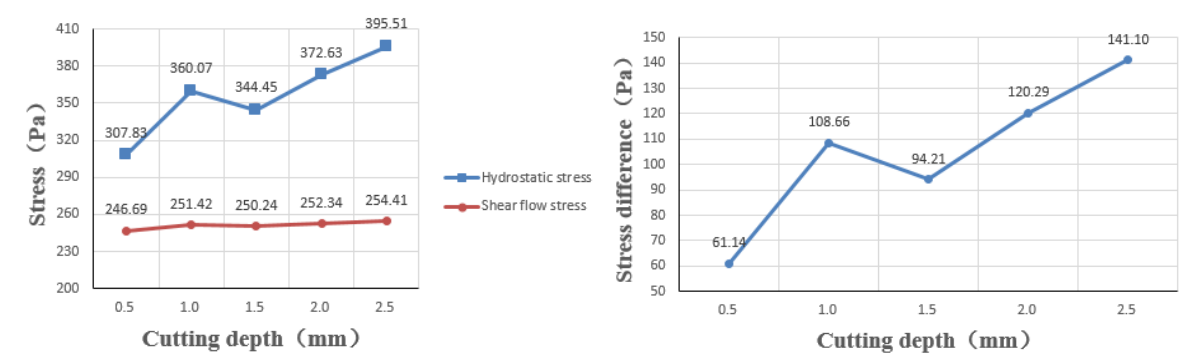

(e)Influence of cutting depth on stress

(f)Influence of cutting depth on stress difference

Figure 4.Influence of cutting parameters on shear flow stress and hydrostatic stress

As it can be seen from Figure 4 (a), with the increase of cutting speed, the hydrostatic and shear flow stress tend to decrease. And the hydrostatic stress decreases more obviously, while the shear flow stress decreases more slightly. As shown in the Figure4 (c), the shear flow stress decreases slowly with the increase of the feed rate, and the variation range is smaller; whereas the hydrostatic stress appears to increase sharply first; slightly increases in the middle; and sharply increases at last. According to the curve in the Figure4 (e), with the increase of cutting depth, the hydrostatic pressure and shear flow stress tend to increase, and the magnitude of hydrostatic pressure increase is larger than the shear stress's. Similarly, comparing the Figure4 (b),Figure4 (d) and Figure4 (f), the gap between hydrostatic stress and shear flow stress in the shear zone decreases with the increase of cutting speed. While the influence of the variation of feed rate on the stress difference is gradually increasing. With the increase of cutting depth, the stress difference shows a trend of increasing. The comprehensive analysis shows that the stress difference between the hydrostatic stress and the shear flow stress is larger when the cutting speed is relatively smaller, the feed rate larger, and the cutting depth larger. When the cutting amount is: $V_{c}=60 \mathrm{~m} / \mathrm{min} 、 \mathrm{f}=0.15 \mathrm{~mm} / \mathrm{r} 、 \mathrm{a}_{p}=1 \mathrm{~mm}$, the stress difference 
between hydrostatic stress and shearing flow stress in the shear zone is the largest, and the even plastic deformation of the material is the best.

\section{Conclusions}

In this paper, cutting experiments were carried out to study the influence of material hardening effect on the cutting process. Through the combination of cutting experiments, calculation and theoretical analysis, this paper draws the following conclusions:

(1)The shear strain increases with the increase of the cutting speed, and then increases with the depth of cutting. The shear strain rate increases with the increase of the cutting speed, With the increase of feed rate gradually decreases, with the increase of cutting depth decreases.

(2) The difference between the hydrostatic stress and the shear flow stress decreases with the increase of the cutting speed, but increases with the feed rate and increases with the cutting depth.

(3) When the cutting amount is: $\square \square=60 \mathrm{~m} / \mathrm{min}, \mathrm{f}=0.15 \mathrm{~mm} / \mathrm{r}$, a $\square=1 \mathrm{~mm}$, the stress difference between the hydrostatic stress and shearing flow stress of the material shear zone is the biggest, and the material has the best plastic deformation, In the course of work to bear the impact load capacity is relatively strong.

\section{Acknowledgement}

This research was financially supported by the National NaturalScience Foundation of China(51265005)(51665007).

\section{References}

[1] R.C. Yang, Y. Xia, T.L. Hu, A. Zhang, Tensile strain hardening behavior of several kinds of stainless steels, J. Lanzhou University of Technology. 37(2011)5-8.

[2] X.F. Zhou, R.Y. Fu, Y. Su, et al. Tensile Strain Hardening Behavior of Fe - Mn - C TWIP Steels, J. Iron and steel. 03(2009)71-74.

[3]Z.F. Wang, W.H. Kong, Effect of Strain Rate on Strain Hardening Behavior of 304 Austenitic Stainless Steel,J. Pressure vessels. 07(2013)6-11.

[4] H.Y. Yu, Comparative study on strain hardening models of thin metal sheet,J. Forging and Stamping Technology. 37(2012)1-6.

[5] Y. Yang, W.W. Zhu, M. Li, Construction of material constitutive model during cutting process for aeronautical titanium alloy based on orthogonal cutting theory, J. The Chinese Journal of Nonferrous Metals. 24(2014):1259-1267.

[6]M.Terhorst, O. Ozhoga-Maslovskaja, D. Trauth,etal, Finite Element-Based Modeling of Strain Hardening in Metal Forming ,J.Steel Research International. 87(2016)1323-1332.

[7]M.Bambach, I.Sizova, S.Bolz, S.Weiss, et al, Devising Strain Hardening Models Using Kocks-Mecking PlotsA Comparison of Model Development for Titanium Aluminides and Case Hardening Steel, J. Metals. 6(2016)204: 1-18.

[8]Y.Z. Zhang, Metal cutting theory, Aviation Industry Press, Beijing, 1988. 